on the surface of the duodenum and upper jejunum, but no lesion was found here or in the ileum. The gall-bladder and pancreas were normal. The caecum was delivered, and immediately a gangrenous appendix was seen. It had not perforated. Appendicectomy with invagination of the stump was performed and the abdomen closed without drainage.

On section the appendix showed a hard faecalith impacted about $\frac{1}{2}$ in. $(1.25 \mathrm{~cm}$.) from the base. Distal to this point the lumen of the appendix was filled with foul-smelling dark bloodstained mucopus. The mucosa was gangrenous and showed patchy ulceration. Recovery was uninterrupted, and the patient was discharged on Feb. 26.

\section{Case 2}

At 3 p.m. on March 10, 1948, the patient, a schoolgirl aged 14 , slipped while turning a somersault on the horizontal bar, which struck her across the centre of the abdomen. She continued with her exercises, but about three hours later experienced colicky abdominal pain, which became worse during the night. She vomited twice, after which the pain localized in the right iliac fossa. She had diarrhoea twice during the night. There was no abnormality of micturition or of menses. She had no history of a previous similar attack. The patient was admitted to hospital at 2.30 p.m. on March 11, 24 hours after receipt of the abdominal injury.

On examination the temperature was $100^{\circ} \mathrm{F} .\left(37.8^{\circ} \mathrm{C}\right.$.), pulse 100 , respirations 20 . The patient was flushed and had a rather dry tongue. Fetor oris was present. There was marked tenderness with muscular guarding and "release" pain confined to the right iliac fossa. Rectal examination revealed well-defined tenderness towarós the right side of the pelvis. The urine contained no abnormal constituents. The blood pressure was 110/80. A diagnosis of acute obstructive appendicitis was made.

Operation.-Under thiopentone, $0.5 \mathrm{~g}$., nitrous-oxide-etherand-oxygen anaesthesia, a McBurney muscle-splitting incision was made, and a gangrenous appendix lying towards the brim of the pelvis was found. It had not perforated. Appendicectomy with invagination of the stump was performed. The abdomen was closed without drainage. On section the appendix was found to have a faecalith impacted in its lumen, just distal to its base. Beyond this point the appendix contained light reddish-brown mucopus. The mucosa showed gangrenous patches. Recovery was uneventful, and the patient was discharged home on March 18.

\section{Commentary}

It is interesting to observe that both cases had a faecalith impacted in the lumen of the appendix. It is reasonable to conjecture that the increased intra-abdominal pressure resulting from the abdominal injury might conceivably force a faecalith already formed at the base of the appendix more distally into the lumen, thereby precipitating an attack of acute obstructive appendicitis.

One might justifiably conclude in a case of acute appendicitis immediately following abdominal trauma, where the presence of a faecalith impacted in the lumen of the appendix was found at operation, that the injury was a contributory and causative factor of the attack.

I should like to thank Mr. D. G. C. Tasker for his interest in and advice on this paper.

\section{REFERENCES}

Boyd, W. (1947). Textbook of Pathology, p. 525. Philadelphia. Murphy, J. B. (1908). In Keen's Surgery, 4, 736. Philadelphia.

Romanis, W. H. C., and Mitchiner, P. H. (1937). Science and

Practice of Surgery, 6th ed., vol. 2, p. 702.

On July $6 x$-ray and electro-medical apparatus worth $£ 3,500$ was officially handed over to the Children's Clinic of Poznan University, Poland, by the General Sikorski Memorial Hospital Fund. A ceremony was held at Century House (Philips Electrical, Ltd.), London, makers of the equipment. His Excellency the Polish Ambassador, representing Poznan University, received an illuminated scroll commemorating the event from Mrs. E. d'A. Willis and Major Rowland Sanders, Trustees of the General Sikorski Memorial Hospital Fund.

\section{Medical Memoranda}

\section{A Case of Intrauterine Amputation due to External Trauma}

The following case is recorded because of its apparent rarity. Search of the literature has failed to reveal any case exactly similar, although undoubtedly such cases have occurred-e.g. during air raids-without being recorded.

\section{CASE History}

A second gravida aged 27 was admitted to hospital at 3 p.m. on March 30, 1946, about one and a half hours after a motor accident in which she had been thrown out of the near-side window on to the grass verge, where she had been pinned down for about 30 seconds by the running-board of the overturned car, which had come to rest across her abdomen. She stated that she was about $5 \frac{1}{2}$ months pregnant, the pregnancy being normal, as had been her previous pregnancy and confinement. She complained of constant severe pain over the whole abdomen ; there had been no vomiting or loss of consciousness, and she felt quite well apart from the abdominal pain.

On examination the temperature was $97.6^{\circ} \mathrm{F}$. $\left(36.4^{\circ} \mathrm{C}\right.$.), pulse 74 respirations 18 , B.P. $125 / 80$; there were no abnormal physical signs in the respiratory, cardiovascular, and central nervous systems. Examination of the abdomen showed a uterine swelling corresponding in size to a 24-weeks pregnancy ; the foetal heart was heard faintly, but no foetal movements were detected, though the patient stated that she had felt movements since the accident. There was a transverse linear bruise at the level and to the right of the umbilicus overlying an area of deep tenderness. There was no abdominal rigidity or muscular guarding and no evidence of free fluid in the peritoneal cavity. The uterus was not actively contracting and gave no sensation of "woodiness." Bleeding per vaginam did not occur and a vaginal examination was not made.

Morphine, $1 / 6 \mathrm{gr}$. (11 mg.), was given every four hours, and the patient passed a quiet night. The following morning her condition was not materially altered. There was no abdominal pain. The foetal heart was still thought to be heard, but the height of the uterus had increased to that of a 28-weeks pregnancy, and there was slight vaginal bleeding. Accidental haemorrhage was provisionally diagnosed, and conservative treatment consisting of " nembutal," $1 \frac{1}{2}$ gr. $(0.1 \mathrm{~g}$.) eight-hourly, progesterone, $1 \mathrm{ml}$. on alternate days, and "ephynal," 1 tablet thrice daily, was given for three days. During this time the foetal heart was not heard, there was no increase in size of the uterus, and no further vaginal bleeding.

Five days after admission (April 3) she had a brisk vaginal haemorrhage, losing approximately $30 \mathrm{oz}$. $(850 \mathrm{ml}$.) of bright blood. Rectal examination revealed that the cervix was three fingers dilated and that the membranes were bulging. The patient was having weak but regular pains and the height of the fundus had fallen to the level noted on admission. Twenty-four hours later there was spontaneous delivery of a 26-weeks foetus, followed immediately by the placenta and about $10 \mathrm{oz}$. $(280 \mathrm{ml}$.) of old blood. She was given $1 \mathrm{ml}$. of ergometrine intramuscularly and the uterus contracted firmly.

The foetus was normally developed and showed early signs of maceration. The left leg was almost completely severed from the body at the level of the anatomical neck of the femur, remaining attached only by the fibres of the quadriceps muscle. The remaining muscles had been neatly divided at the level of fracture of the femur. Apparently the foetus had been lying in the R.O.P. position at the time of injury, whereby the impact of the running-board of the car had been transmitted to the posterior surface of the left thigh, resulting in an almost complete traumatic amputation of the limb in utero.

A detailed examination of the foetus was impossible, as it was unfortunately disposed of by mistake before further examination could be made.

It is worthy of comment that the foetus, which was relatively well protected by its position and its covering, should have suffered severely, while the uterine and abdominal walls, which were subjected to the direct impact, showed minimal damage.

Our thanks are due to Mr. D. W. Currie, consultant obstetrician, and to Dr. W. McIntosh, medical superintendent, St. James's Hospital, Leeds, for permission to submit these notes for publication.

R. F. LAWRENCE, M.D., M.R.C.O.G. D. SHeRMan, M.R.C.S., L.R.C.P. 